
DCT 7 BEG

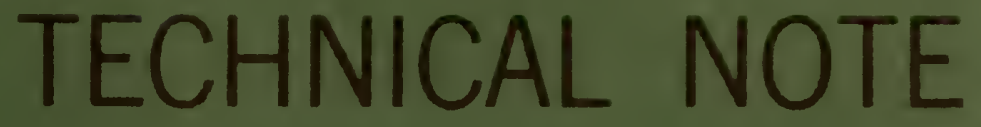

Reference book not to be taken from the library.

\title{
Research on Crystal Growth and Characterization at the National Bureau of Standards June 1966
}

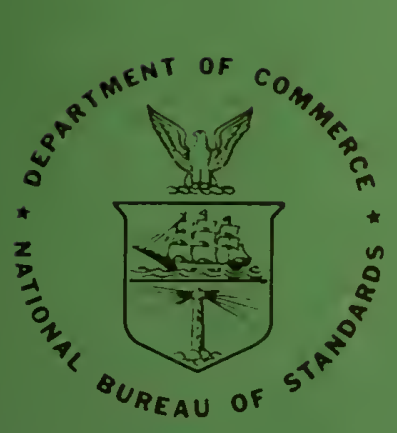

U.S. DEPARTMENT OF COMMERCE National Bureau of Standards 


\section{THE NATIONAL BUREAU OF STANDARDS}

The National Bureau of Standards is a principal focal point in the Federal Government for assuring maximum application of the physical and engineering sciences to the advancement of technology in industry and commerce. Its responsibilities include development and maintenance of the national standards of measurement, and the provisions of means for making measurements consistent with those standards; determination of physical constants and properties of materials; development of methods for testing materials, mechanisms, and structures, and making such tests as may be necessary, particularly for government agencies; cooperation in the establishment of standard practices for incorporation in codes and specifications; advisory service to government agencies on scientific and technical problems; invention and development of devices to serve special needs of the Government; assistance to industry, business, and consumers in the development and acceptance of commercial standards and simplified trade practice recommendations; administration of programs in cooperation with United States business groups and standards organizations for the development of international standards of practice; and maintenance of a clearinghouse for the collection and dissemination of scientific, technical, and engineering information. The scope of the Bureau's activities is suggested in the following listing of its three Institutes and their organizational units.

Institute for Basic Standards. Applied Mathematics. Electricity. Metrology. Mechanics. Heat. Atomic Physics. Physical Chemistry. Laboratory Astrophysics.* Radiation Physics. Radio Standards Laboratory:* Radio Standards Physics; Radio Standards Engineering. Office of Standard Reference Data.

Institute for Materials Research. Analytical Chemistry. Polymers. Metallurgy. Inorganic Materials. Reactor Radiations. Cryogenics.* Materials Evaluation Laboratory. Office of Standard Reference Materials.

Institute for Applied Technology. Building Research. Information Technology. Performance Test Development. Electronic Instrumentation. Textile and Apparel Technology Center. Technical Analysis. Office of Weights and Measures. Office of Engineering Standards. Office of Invention and Innovation. Office of Technical Resources. Clearinghouse for Federal Scientific and Technical Information. **

* Located at Boulder, Colorado, 80302 .

* Located at 5285 Port Royal Road, Springfield, Virginia, 22151. 


\section{NBS TECHNICAL NOTE 293 \\ ISSUED AUGUST 26, 1966}

\section{Research on Crystal Growth and Characterization at the National Bureau of Standards June 1966}

Edited by Harry C. Allen, Jr. Institute for Materials Research National Bureau of Standards

Washington, D.C., 20234

Supported by the Advanced Research Projects Agency

NBS Technical Notes are designed to supplement the Bureau's regular publications program. They provide a means for making available scientific data that are of transient or limited interest. Technical Notes may be listed or referred to in the open literature.

For sale by the Superintendent of Documents, U.S. Government Printing Office Washington, D.C., 20402 - Price 25 cents 

RESEARCH ON CRYSTAL GROWTH AND CHARACTERIZATION

AT THE NAT IONAL BUREAU OF STANDARDS

\author{
Supported by the \\ Advanced Research Projects Agency
}

Edited by

Harry C. Allen, Jr.

\begin{abstract}
The National Bureau of Standards with partial support from the Advanced Research Projects Agency of the Department of Defense is continuing a wide program of studies involving crystalline materials. These include investigation of methods and theory of growth, study of detection and effects of defects, determination of physical properties, refinement of chemical analysis, and determination of stability relations and atomic structure. The types of materials range from organic compounds, through metals, and inorganic salts to refractory oxides. This report summarizes progress in those projects wholly or partially supported by ARPA.
\end{abstract}

Key words: Crystal growth, crystal characterization, and crystalline materials.

\title{
1. INTRODUCTION
}

The National Bureau of Standards continues a wide and active program in many aspects of material research. The NBS has been encouraged by the Advanced Research Projects Agency of the Department of Defense to extend the study of crystals, particularly in the field of crystal growth and has aided with financial support. This report describes briefly the current state of the many projects here in the general field of crystal studies supported by ARPA. These items should be considered as progress reports, not in the nature of finished studies. The formal papers resulting from the work are listed in these pages. 
To aid in integrating the crystal program here and to encourage cross linking between participants in the program, a number of meetings, discussions and lectures have been arranged. In many cases these report and discuss our current work, in others scientists from outside material science centers appear.

\section{CRYSTAL GROWTH}

\subsection{Theory of Morphological Stability of Solids}

Growing by Diffusion or Heat Flow

S. R. Corie11, R. L. Parker

Crystalization of Metals Section

Research has continued on the stability of the shape of particles growing in a diffusion field. Currently, the effect of interface kinetics on the stability is being studied. It has been found that stability is greatly enhanced, by several orders of magnitude in certain cases, if the interface kinetics are slow. The effect of anisotropic surface tension on the stability of a planar interface has also been considered. The effect of the anisotropy has been found to involve the second derivative of the surface tension.

Publications and Talks

S. R. Coriell and R. L. Parker, Role of Surface Diffusion in Stabilizing the Surface of a Solid Growing from Solution or Vapor; J. App1. Phys., 37, 1548 (1966).

S. R. Coriell and R. L. Parker, Interface Kinetics and the Stability of the Shape of a Solid Sphere Growing from the Melt; International Conference on Crysta1 Growth, Boston, Mass., June 20-24, 1966.

\subsection{Interface Kinetics of Growth of}

Metal Crystals from the Melt

J. G. Early, H. Utech, W. S. Brower

Crystallization of Metals Section

Studies have been initiated to study thermal convection effects on crystal growth. Apparatus has been constructed and experiments have been carried out on convection effects in several tin-bismuth alloys under controlled freezing conditions. Experiments have been 
planned and will shortly be initiated to study possible convection effects on the interface kinetics of growth. These experiments will determine possible effects of experimental geometry on the technique for studying interface kinetics.

Publications and Talks

H. P. Utech, W. S. Brower and J. G. Early, The Effects of Thermal Convection on Crystal Growth in Horizontal Boats; International Conference on Crystal Growth, Boston, Mass., June 20-24, 1966.

\subsection{Electrodeposition of Single Crystals F. Ogburn, J. Smit}

Electrolysis and Metal Deposition Section

Efforts at crystal fabrication were confined to the deposition of silver from solutions of reagent grade silver nitrate in distilled water. The deposition equipment was designed so that the cathode potential or current could be held constant at any predetermined value. Measurements were made of the electrical current, cathode potential and rate of growth of individual dentrites.

The character of the crystalline silver deposits is highly dependent on deposition conditions. In the course of the present investigation it was observed that non-metallic impurities in the silver nitrate appeared to prevent or discourage the growth of dendrites and crystal facets. However, prolonged electrolysis reduces the impurity level sufficiently to permit reproducible dendritic growth and faceting. At high cathode potentials, dendrites grow rapidly with extensive branching. Decreasing potentials reduce branching and also reduce the growth rate of individual dendrites. A further reduction in potential results in monoacicular growth. At still lower potentials acicular growth ceases and equiaxed growth commences.

The progress of a single acicular growth has been observed while varying the cathode potential. In so doing it was possible to determine the growth rate as a function of the cathode potential. Growth rates of up to $25 \mathrm{~mm} / \mathrm{h} \quad(70,000 \AA / \mathrm{s})$ were observed.

A combination of optical and optical goniometric, metallographic and $x$-ray diffraction techniques are used to determine dendritic morphology and structure. To this time, however, only acicular deposits have been examined. These examinations have revealed, in every case, a twin structure or structures in the subject specimen. 
To this point no less than five distinct twin and multiple twin structures have been uncovered. As expected for the F.C.C. system the $x$-ray diffraction patterns indicate the (111) plane to be the composition plan of the twin structure and $<110>$ direction to be the growth direction of the dendrites. An exception to the above occurred in a dendrite of planar form grown from a purposefully doped solution containing an additional metal ion. In this case the direction of growth proved to be the <112> direction. The twin composition plane remained the (111) plane.

Twin boundaries, parallel to the growth direction, are always present in the silver dendrites and, hence, seem to participate in the growth mechanism, possibly from a re-entrant angle mechanism rather than a dislocation mechanism. Unfortunately, no clear cut picture of the role of twinning with respect to acicular growth exists at this time. Several twin boundary configurations have been observed and may possibly be related to the dendritic growth rate. This is yet another aspect of the general problem that needs elucidation.

\subsection{Copper Crystal Growth}

A. F. Clark, J. J. Gniewek, J. C. Moulder and R. L. Powe11 Cryogenic Properties of Solids Section

Copper is used extensively by the solid state physicist to study transport properties, band structure, and Fermi surface effects. The effective electronic purity of large copper crystals available one year ago (resistance ratios of 2000 to 4000) was not good enough for many measurements. During the last year project members developed methods and produced copper crystals that are an order of magnitude better than those previously available: electrical resistance ratios of over 40,000 (the last single crystal was 44,000), chemical impurities of $0.1 \mathrm{ppm}$ or less for any impurity, and physical dislocation densities of about $10^{6} / \mathrm{cm}^{2}$

The crystals are grown by a modified Bridgman technique in a graphite-1ined quartz crucible with a vacuum of about $10^{-5}$ torr. The heating is supplied by an induction furnace; about $3 \mathrm{~kW}$ is necessary to melt the boules. After solidification and re-cleaning the boules are transferred to an annealing furnace for a long time anneal (up to one week) at $1000^{\circ} \mathrm{C}$ in a controlled oxidizing atmosphere. With short anneal times there is a very marked impurity gradient toward the center of the boule.

The production boules are about $2.9 \mathrm{~cm}$ in diameter and over $3.0 \mathrm{~cm}$ long. Smal1 oriented samples have been effectively sparktrepanned from the larger boules. Studies on the damage of spark 
machining show that even on fine cutting ranges there is significant damage within $0.2 \mathrm{~mm}$ of the surface. Methods have also been developed for controlled etching and removal of the damaged surfaces.

Two serious problems remain to be solved. First, most of the boules are not single crystals, but contain many striation regions that make the boule unusable. Their exact cause is still unknown. Until that problem is solved the method remains inefficient. Second, controlled dilute impurity crystals should be prepared in order to test various theories of impurity effects in the ideal limit of an almost pure crystal. Dilue impurity crystals would be very helpful in several metal physics experiments.

\section{Publications}

J. J. Gniewek, A. F. Clark and J. C. Moulder, Spark Planning Damage in Copper; NBS Tech. Note 321 (1965).

J. J. Gniewek and A. F. Clark, Preparation of Copper Crystals with Low Electrical Resistivity; J. Appl. Physics 36, 3358 (1965).

\subsection{High Temperature Crystal Growth from Solvents}

\section{H. S. Parker}

\section{Crystal Chemistry Section}

The development and evaluation of methods for the growth of highly perfect crystals at temperatures below the melting point of the crystal and to obtain an understanding of the parameters affecting the growth process continued. The technique of temperature gradient zone melting, proposed by Pfann (Trans. AIME 203, 961 [1955], is currently being investigated to determine its applicability to crystal growth of oxides having the scheelite (CaWO ${ }_{4}$ structure. As a potential laser host, crystals having this structure are of technological as well as scientific interest.

During this reporting period, the major effort has been directed towards the growth of crystals of $\mathrm{CaMoO}_{4}$ using $\mathrm{Li}_{2} \mathrm{SO}$ as the solvent. The temperature gradient zone melting technique involves causing a thin layer of solute plus solvent to traverse a sandwich composed of single crystal seed/( solute + solvent)/ source material by placing the assemblage in a temperature gradient. 
Stable zones have been formed successfully and regrowths of the order of 1 - $2 \mathrm{~mm}$ have been obtained at temperatures in the $800-960^{\circ} \mathrm{C}$ temperature range, which is $500-650^{\circ} \mathrm{C}$ below the melting point of $\mathrm{CaMoO}_{4}$. Orientation and preliminary etch pit studies of the regrown crystals Indicate that the orientation of the seed is preserved in the regrown crystal and that the number of dislocations is reduced by approximately an order of magnitude as compared with the Czochralski-grown material.

The temperature gradient and temperature in the zone region have been measured during a growth run, and it was found that the $\Delta \mathrm{T} / \Delta \mathrm{x}$ was $250^{\circ} \mathrm{C} / \mathrm{cm}$ at an average temperature of $815^{\circ} \mathrm{C}$ for the zone. The measurements of temperature were made by inserting small $(0.025 \mathrm{~mm} \times 0.5 \mathrm{~mm})$ thermocouple junctions into the sandwich assembly and "growing" them in place by passing a solvent zone through the assembly before the actual growth experiment and temperature measurements were made.

In order to establish the liquidus slope in the $\mathrm{CaMoO}_{4}-\mathrm{LI}_{2} \mathrm{SO}_{4}$ system, a series of liquidus determinations has been carried out at concentrations of $\mathrm{CaMoO}_{4}$ ranging from the eutectic composition, $\sim 15$ weight percent $\mathrm{CaMoO}_{4}{ }^{4}$, to 50 weight percent $\mathrm{CaMoO}_{4}$. Liquidus temperatures ranged from $20^{\circ} \mathrm{C}$ to $1022^{\circ} \mathrm{C}$. The average $e^{4}$ iquidus slope over the temperature range where the crystal growth experiments were conducted was found to be 0.14 weight percent per $1{ }^{\circ} \mathrm{C}$.

Tiller (J. App1. Phys. 34, 2757 [1963] has suggested that the zone travel rate should depend on the zone size and growth mechanism as well as other factors such as the temperature gradient. A series of growth experiments is in progress to see if this phenomenon is evident in this system for zone thicknesses ranging from $1.3 \times 10^{-3}$ to $8.4 \times 10^{-2} \mathrm{~cm}$. Although the measurements are not completed, a dependence is apparent.

Measurements of the 1ithium concentration profile across the specimens in the direction of zone travel are currently being made.

Talks

H. S. Parker, The Growth of $\mathrm{CaMoO}_{4}$ by a Temperature Gradient Zone Melting Technique, International Conference on Crystal Growth, June 20-24, 1966. 


\subsection{Kinetics of Crystal Growth from Solution}

\section{J. L. Torgesen, R. W. Jackson}

The growth on the $\{100\}$ plane of ammonium dehydrogen phosphate (ADP) in solution is by a screw dislocation mechanism. The growth spirals are elliptical in shape with the short axis parallel to the $\{001\}$ plane of the crystal. Neighboring dislocations of opposite hand (Trank-Read) are common. Growth on the $\{101\}$ plane of ADP proceeds by the movement of layers from the edges toward the center of the face. Complete layer annihitation is frequent. If $\mathrm{Cr}^{+3}$ ion is added to the growth bath as an impurity the growth spirals on $\{100\}$ assume a rectangular shape but no observable changes in layer morphology on $\{101\}$ are produced.

Growth layer morphology and growth mechanism effects have been studied microscopically on the $\{100\}$ and $\{101\}$ faces of ammonium dehydrogen phosphate (ADP). Studies were made on solutions of pure ADP and solutions contaminated with $\mathrm{Cr}^{+3}$ by means of a microscope attachment developed here. Complete reversibility of the growth spiral shapes is evident. This reversibility correlates with the habit effects and $\mathrm{Cr}^{+3}$ impurity retention in macro-growth systems. Single crystals grown for a time in $\mathrm{Cr}^{+3}$ contaminated solution, producing tapered habit and retention of $\mathrm{Cr}^{+3}$ in the tapered vicinal faces $\{100\}$, revert to the normal habit on the addition of ethylene-dramine tetraacetic acid which complexes with the $\mathrm{Cr}^{+3}$ thus inhibiting the $\mathrm{Cr}^{+3}$ activity.

The growth morphology of single crystals of sparingly soluble salts grown in a silica gel medium has proved difficult to study microscopically because of excessive light scattering in the gel. Work is continuing on this'problem with particular attention begin paid to the transition from the initially formed yellow phase of $\mathrm{HgTz}$ to the red phase.

Publications and Talks

J. L. Torgesen and R. W. Jackson, Growth Layers in Ammonium Dehydrogen Phosphate; Science 148, 952 (1962). 
2.7 The Crystallization Habits of Organic Polymers

\section{F. Khoury and J. D. Barnes \\ Polymer Physics Section}

The general objective of this project is to characterize the crystallization habits exhibited by organic polymers, when they are crystallized both from solution and from the melt, with a view of providing a broad basis of understanding the mechanisms of crysta1lization of these long chain substances at the molecular level.

A paper entitled "The Spherulitic Crystallization of Isotactic Polypropylene from Solution: On the Evolution of Monoclinic Spherulites from Dendritic Chain-Folded Crystal Precursors" has been published. The study reported therein provides a detalled insight into the nature and origin of the atypical mode of growth and morphology of monoclinic spherulites of polypropylene which are not only formed on crystallizing the polymer from concentrated solutions, but which also represent the most common form of crystallization of the polymer from the melt. It is shown that such spherulites evolve from dendritic crystal precursors which propagate through a mode of twinning involving an $80^{\circ}$ change in orientation of the chain molecules in secondary chain-folded lamellar branches with respect to that in primary branches. This mode of twinning which is exceptional to polypropylene is the source of the fundamental differences between the mode of development of monoclinic polypropylene spherulites and that generally assoclated with the formation of spherulites in other polymers.

A study has been carried out during the past year of the growth habits exhibited by polychlorotrifluoroethylene crystals grown from dilute solutions of the polymer in low molecular weight polychlorotrifluorethylene oll over a range of temperatures. Lamellar crystals have been grown which exhibit various degrees of curvature, while planar or nearly planar chain folded lamellae are formed at low supercoolings, high supercoolings yield hollow bowl shaped crystals whose walls posses a laminated structure consisting of several superimposed chain folded lamellae, each of which consists of a mosaic of fold domains. The progressive transition in the habit of the lamellar crystals from planar to highly curved with increasing supercooling parallels in many respects an analogous trend which has been previously observed on crystallizing poly(4-methylpentene1) from solution. A preliminary study of the crystallization of polyoxymethylene from solution has also indicated that curved lamellar crystals of this polymer are also formed at high undercoolings. These various observations suggest that the formation 
of curved lamellar crystals of polymers is a phenomenon of somewhat general occurrence under conditions which favor rapid crystallization. While this phenomenon and the elucidation of its origin on a structural basis is of interest per se, it is all the more interesting in view of evidence which suggests that it is intrinsically assoclated with the as yet not fully understood growth processes leading to the formation of the more common types of spherulitic structures in polymers.

Two papers are in the process of completion in which the formation of curved crystals of poly(4-methylpentene-1) and poly(chlorotrifluoroethylene) are described and in which the possible nature of the structural factors leading to the formation of such crystals are discussed. In particular, the influence of lattice distortions induced by the molecular folds in the constituent lamellae of such crystals is considered.

Additional studies are planned with a view of establishing whether the phenomenon of curved crystal formation is of more general occurrence. The bearing of this phenomenon and its origin In relation to the mechanism of growth of the common types of spherulitic structures in polymers will be investigated further.

\section{Publications}

F. Khoury, The Spherulitic Crystallizations of Isotactic Polypropylene from Solution, J. Research, NBS, 70A, 29 (1966).

2.8 The Crystallization Kinetics of Multi-Component Systems

J. I. Lauritzen, Jr., E. A. DiMarzio, and E. Passaglia

Polymers Division, Polymer Physics Section

In systems consisting of several components there are a number of kinetic problems which can be considered as the kinetics of growth of a "mixed chain", 1 .e., a chain whose $\underline{\nu}^{\prime}$ th unit may be any of the components of the system. Examples of such systems are (1) a mixture of monomers which polymerize to form a copolymer, (2) a mixture of several components which crystallize to form a solid solution, the chain in this case being the growth of a crystal strip at, say, a screw dislocation edge, (c) a polymer melt or solution crystallizing to form a chain folded crystal, the chain being a strip growing on the edge of crystal and the "components" being the possible lengths of the segments of molecules between folds. 
In these problems it is desirable to be able to calculate the rate of growth of the chain as a function of the relevant parameters of the system, the average composition of the chain at various rates of growth, and the various pair and higher distributions. A theory which permits the calculation of these quantities has been formulated, and a MS has been prepared for publication.

\subsection{Thermal Generation of Vacancies and Substitutional}

\section{Sites in Crystalline Polymers}

\section{G. T. Davis and R. K. Eby}

Polymer Physics Section

The thermal expansion of the macroscopic specific volume of polyethylene exceeds that of the unit cell. It has been proposed that this may result from thermal generation of vacancies and substitutional sites (Eby, 1962). There are a number of limitations on the data needed to test experimentally either this or any other proposal: reversible with temperature, lattice and volume measurements on the same sample, very accurate measurements, samples isothermally crystallized, samples of well characterized fractions as well as whole polymer, and measurements of the lamella thickness of the samples used. Data satisfying these requirements have not been avallable. Therefore, apparatus and samples have been prepared to obtain these data. A stirred bath has been developed for dilatometric measurements between -135 and $+60^{\circ} \mathrm{C}$ and a commercial $x$-ray cell has been modifled for use in the same range. (This range can be extended for both measurements.) Initial results for fractions and whole polyethylene are consistent with the thermal generation of vacancies and new substitutional sites. This work has been reported at the March 1966 Meeting of the American Physical Society.

Publication

R. K. Eby, J. App1. Phys. 33, 2253 (1962).

2.9 Point Defects in Crystalline Copolymers

J. P. Colson, L. H. Bolz, and R. K. Eby

Polymer Physics Section

Research concerning the inclusion of perfluoromethyl groups as point defects in the crystals of copolymers of tetrafluoroethylene 
and hexafluoropropylene has been briefly reported in NBS Technical Note 260. Two papers discussing this work have been published.

Publications

L. H. Bolz and R. K. Eby, J. Research NBS 69A, 481 (1965) and

J. P. Colson and R. K. Eby, J. Appl. Phys. $\underline{37}$, July (1966).

This work which has not been reported before has been published in J. Acoust. Soc. Am 39, 506 (1966). (R. K. Eby and J. P. Colson)

2.10 Homogeneous Nucleation Studies

J. D. Hoffman, G. S. Ross and L. J. Frolen

and

F. Gornick

Polymers Division

During the current report period, studies of the isothermal rate of homogeneous crystal nucleation in highly supercooled melts of unfractionated linear polyethylene have been completed. The temperature dependence of the nucleation rate was determined and analysed in accord with current theories of homogeneous nucleation of chain-folded polymer crystals. Statistical analysis was accomplished by means of OMNITAB computer program. An estimate of the quantity $\left(\sigma^{2} \sigma_{e}\right)$ was determined when $\sigma$ and $\sigma_{e}$ are respectively the lateral and end-surface free energies of the crystal. If the melting point of polyethylene is assumed to be $417.86^{\circ} \mathrm{K}$ then $\left(\sigma^{2} \sigma_{e}\right)$ is 8068. Combining this value with an independent estimate of $\sigma=9.6$ ergs $\mathrm{cm}^{-2}$, a value of 87.5 ergs $\mathrm{cm}^{-2}$ is obtained for the chain folded surface.

Isothermal, radial growth rates for spherulites of unfractionated polyethylene have also been measured. These experiments give an estimate of $\left(\sigma \sigma_{e}\right)$. Again using the values of $417.86^{\circ} \mathrm{K}$ for the melting point and $9.6 \mathrm{ergs} \mathrm{cm}^{-2}$ for $\sigma$, the calculated value for $\sigma_{e}$ is 80.4 ergs $\mathrm{cm}^{-2}$ which is in good agreement with the value obtained from the nucleation experiments.

The program developed for "PILOT" by Dr. George Moore of the Metallurgy Division for counting procedures has been further 
investigated and was found to be unsatisfactory in its present state for these studies. However, experimental techniques for preparing samples which are stable for several months have been developed. Consequently the same field can be used for many experiments and are counted by a comparative technique which allows individual droplets to be identified and their freezing behavior from experiment to experiment to be studied.

Droplet experiments on one fraction $(50,000 \mathrm{Mw})$ of linear polyethylene have been completed and are presently being analysed. The preliminary value for $\sigma_{e}$ is 95.7 ergs $\mathrm{cm}^{-2}$. Slow cooling and spherulite growth experiments are currently in progress and are expected to be completed within the next two months.

During the next reporting period the dependence of the nucleation and growth rates upon molecular weight will be investigated using several fractions of polyethylene prepared in this laboratory.

Publications and Talks

J. D. Hoffman, Nucleation Controlled Crystal Growth and ChainFolding in Polymers, International Conference on Crystal Growth, Boston, Massachusetts, June 21-24, 1966.

F. Gornick, Crystal Nucleation in Polyethylene: The Droplet Experiment, International Conference on Crystal Growth, Boston, Massachusetts, June 21-24, 1966.

F. Gornick and J. D. Hoffman, Nucleation in Polymers, Ind. Eng. Chem. $\underline{58}, 41$ (1966).

J. D. Hoffman, Theoretical Aspects of Polymer Crystallization with Chain Folds: Bulk Polymers. SPE Transactions, J, 1, (1964).

2.11 Nucleation Rate of Polymer Crystals

J. D. Hoffman and James J. Weeks, Jr.

Polymers Division

The analysis of the data for the crystallization of Polybutene-1 from the subcooled liquid to form II crystal was completed. A paper giving the results of the investigation has been published.

A 64,600 molecular weight fraction of polyethylene was used to obtain low-angle $\mathrm{X}$-ray diffraction data during crystallization and melting of the sample. The smaller of the two main low-angle spacings $\left(L_{2}\right)$ most closely agrees with the lamellar thickness previously determined by Frank Anderson of Chemstrand on this same sample by means of electron microscopy.

The larger spacing $\left(\mathrm{L}_{1}\right)$ 
corresponds exactly to the width of Anderson's type II lamellae. By making diffraction scans during melting, it was found that the $L_{2}$ peak was not shifted to larger spacings as had been expected; whereas, the $\mathrm{L}_{1}$ peak did shift toward smaller angles. The uniformity and temperature dependence of lamellar width are still unexplained.

Publication

J. Powers, J. D. Hoffman, J. J. Weeks, and F. A. Quinn, Jr.; Crystallization Kinetics and Polymorphic Transformations in Polybutene-L; J. Research NBS 69A, 335 (1965).

\section{CRYSTAL CHARACTERIZATION}

\subsection{Soft X-ray Spectra of the Solid State}

R. D. Deslattes and B. Paretzkin

Crystal Chemistry Section

The $x$-ray topographic work has continued to produce results. The mismatched minus position topography has been perfected by the production of a set of six perfect reference crystals which permit strain microscopy of arbitrary specimen with a nolse level more than an order of magnitude below the part per million level.

The sensitivity of the method has enabled the undertaking of several interesting problems involving a better understanding of the physics of the technique or more detailed materials characterization. Some of these areas are, (1) mechanisms of image formation, (2) surface relaxation of strain fields about single dislocations, (3) point defect measurements such as the measurement of lattice parameter changes associated with the diffusion of foreign atoms into host lattices, device type application of the measurements to integrated circuits and a potentially new system of geochronology based on the isotopic variability (as revealed by strain) in perfect natural crystals of silicates anil borates.

Further, the ability to produce perfect single crystals finds applications in metrology. Some examples are angle standards, an atomic mass standard and density standards.

Publications and Talks

R. D. Deslattes, H. S. Peiser, J. A. Beardon and J. S. Thomsen, Metrologia, July 1966. 


\subsection{Crystal Defect Studies by Optical Means}

R. F. Blunt and M. I. Cohen

Solid State Physics Section

Color centers, produced mainly by $50 \mathrm{kV}$ x-rays, have been studied in the rutile structured $\mathrm{MgF}_{2}$, largely at room temperature. An initial slightly anisotropic absorption band near $260 \mathrm{~nm}$ is tentatively identified as an F-center. Subsequent optical bleaching results in the formation of a strong band at $370 \mathrm{~nm}$ and several weak bands including one at $320 \mathrm{~mm}$. Both of these appear only for $E \perp c$ and are believed to be due to M-centers. The choice of modeIs is dictated in part by the observation of typical trapped electron ESR spectra in irradiated samples. Bleaching studies show that the $320 \mathrm{~mm}$ band arises from "centers" lying along the [110] directions, while the $370 \mathrm{~nm}$ band seems to be cylindrically symmetric about the c-axis, and also that the $320 \mathrm{~nm}$ is reversibly converted into the $370 \mathrm{~mm}$ band. Selection rules have been derived for $(1 s)^{2} \rightarrow$ (1s2p) transitions in each of the four possible M-center configurations permitted in the rutile structure. It is found that of the two "types" having F-F bands in the (001) plane, one identifies rather well with the $370 \mathrm{~nm}$ band and the other with the $320 \mathrm{~mm}$ band.

An investigation of the extrinsic and intrinsic properties of the absorption edges of $\mathrm{SrTiO}_{3}, \mathrm{TiO}_{2}, \mathrm{Cu}_{2} \mathrm{O}$ and other "oxides" is under way. A detailed measurement of the absorption edge of $\mathrm{SrTiO}_{3}$ has been made and the edge is found to obey the Urbach rule over at least five orders of magnitude. Similar measurements on $\mathrm{TiO}_{2}$ for comparison are in progress.

Work has commenced on the application of certain of the recently devised "modulation" techniques to the study of the absorption edge and band structure of crystals. An electroreflectance apparatus of the "Cardona" type has been constructed and measurements made on a number of crystals including $\mathrm{SrTiO}_{3}, \mathrm{TiO}_{2}, \mathrm{BaTiO}_{2}, \mathrm{Cu}_{2} \mathrm{O}$, InSb, and $\mathrm{CdS}$.

Publications

R. F. Blunt, Optical Absorption of Cobalt in Maganese Fluoride,

J. Chem. Phys . 44, 2317 (1966). 
3.3 Crystal Defect Studies using Magnetic Resonance

Te-Tse Chang

Solid State Physics Section

A superheterdoyne detection system at $x$-band frequency has been assembled and is completed. It was estimated that this system would be able to detect signals as low as $10^{-13}$ to $10^{-14}$ watt. This is about an order of magnitude better than the usual commercially available superheterodyne detection systems for general usage. With this detection system, the EPR spectrum of $\mathrm{Mo}^{5+}{ }^{2} \mathrm{TI} \mathrm{TO}_{2}$ at $4^{\circ} \mathrm{K}$ was detected and recorded for the first time, since very low microwave power has to be used to avoid saturation effects. Furthermore, the saturation and relaxation effects of $10^{5+}$ EPR transitions can now be studied. It was found that the relaxation rate approaches a Inear temperature dependenge below $1.5^{\circ} \mathrm{K}$, varies as (temp) 5 up to $3^{\circ} \mathrm{K}$, and approaches (temp) dependence at $3{ }^{\circ} \mathrm{K}-4^{\circ} \mathrm{K}$. At $77^{\circ} \mathrm{K}$ and up to $150^{\circ} \mathrm{K}$, the usual solid state diode detector was used to observe the Mo5+ EPR signal; the line-width measurement revealed that the relaxation rate is (temp) dependent above $77^{\circ} \mathrm{K}$ and approaches a higher order dependence above $130^{\circ} \mathrm{K}$. No Orbach relaxation process was found.

EPR signals from conduction electrons in $\mathrm{SrTiO}_{3}$ and color centers in $\mathrm{MgF}_{2}$ are currently under detailed study. The signals were weak and broad. With superheterodyne detection, the spectrum may be more readily resolved. Current efforts are spent on identification and interpretation of those signals.

3.4 Thermal Conductivity of Paramagnetic Salts

J. F. Schooley

Cryogenic Physics Section

A new vibrating-coil magnetometer for measuring the magnetic moment, $M=0.08 \mathrm{H}$, for $\mathrm{H}$ less than 1 De and at temperatures less than $0.3^{\circ} \mathrm{K}$ was completed and moment data obtained. The magnetic moment data obtained on $\mathrm{SrTiO}_{3}$ specimens were correlated with semiconductivity and superconductivity theorles and with specific heat data. The superconducting transition temperatures of a series of ceramic strontium titanate, barium-doped strontium titanate, and calcium-doped strontium titanate were examined using a mutual inductance bridge operating at $270 \mathrm{c} / \mathrm{s} 0.01 \mathrm{Oe}$. 
Publications and Talks

R. S. Kaeser, E. Ambler and J. F. Schooley, Vibrating Coil Magnetometer for use at very Low Temperatures, Rev. Sci. Inst. $\underline{37}, 173(1966)$.

H. P. Frederikse, J. F. Schooley, R. W. Thurber, E. Pfeiffer and W. R. Hosler, Superconductivity in Ceramic Mixed Titanites, Phys. Rev. Letters, 16, 579 (1966).

E. Ambler, J. H. Colwell, W. R. Hosler and J. F. Schooley, Magnetism and Critical Fields in $\mathrm{SrTiO}_{3}$. (Submitted for publication).

3.5 Magnetic Properties of Salt Single Crystals at Very Low Temperatures

B. W. Mangum

Relaxation times have been measured for $\mathrm{HoCl}_{3}$ and $\mathrm{ErCl}_{3}$ in $\mathrm{LaCl}_{3}$. The results of these measurements have been analysed and published. The spin-lattice relaxation time for concentrated $\mathrm{NdCl}_{3}$ was measured by the audio frequency susceptibility method as a function of temperature at fields up to 100 oe. The results are complicated by the presence of spikes in the susceptibility and are not yet fully understood.

Publications and Talks

B. W. Mangum and R. P. Hudson, Spin-lattice Relaxation in Some Rare Earth Trihalides, J. Chem. Phys, 44, 704 (1966).

B. W. Mangum and R. P. Hudson, Spin-lattice Relaxation of Rare Earth Ions in $\mathrm{LaCl}_{3}$, Bul1. Am. Phys. Soc., Series II, 10, 1109 (1965).

3.6 Nuclear Magnetic Acoustic Resonance

L. H. Bennett

Alloy Physics Section

Work was continued on the study of the nuclear magnetic acoustic resonance of various isotopes by means of tests on single crystal specimens. 
Improvements were made in both the marginal oscillator and the matching circuits whereby improved signal-to-noise ratio resonance figures were secured for the potassium lodide crystal, which is employed as a criteria for testing the equipment.

Whereby resonance was observed on In $^{115}$ in a high purity single crystal of InSb supplied by Texas Instruments, it was not possible to observe the same resonance on an AuIn2 single crystal. This can be attributed to the higher purity, and perfection of structure of the indium antimonide. A new AuIn 2 crystal has been ordered having a higher order of purity than the present crystal.

A tantalum single crystal, secured as the highest available purity produce of several years ago, and with a resistivity ratio of 75 was tested with no resonance being observed. R. H. Gregory and E. H. Bomme1, Phys. Rev. Letters 15, 404 (1965) reported nuclear acoustic magnetic resonance results in more recently produced higher purity tantalum. Of five samples Gregory and Bommel tested only two, namely, of ultrapure Westinghouse tantalum having a resistivity ratio greater than 400 , gave measurable resonances. They observed such resonance with a good signal-to-noise ratio at liquid nitrogen temperatures and with a lower ratio at liquid helium temperatures. Such resonances were not observable at room temperature, which is not understood

Employing single crystal tantalum having a resistivity ratio of 405 with samples and polished to optical flatness and parallelism, it is planned to investigate nuclear magnetic acoustic resonances at test temperature varying from liquid nitrogen to room temperatures.

\subsection{Experimental Determination of Atomic Scattering Factors}

$$
\text { G. Burley }
$$

\section{Crystallography Section}

The $x$-ray atomic scattering factors for magneeium oxide reported previously were further refined, and the results have been published.

Measurement of the scattering factors for copper metal, using molybdenum radiation to minimize the anomalous dispersion correction, has also been completed (Table I). This material was chosen because it is a transition element with electronic configuration $3 \mathrm{~d}^{10} 4 \mathrm{~s}^{1}$, where both the closed d shell and the s orbital are spherically symmetric and a direct comparison of theoretical and experimental results is possible. As expected, the experimental values are 
very near those calculated by the Hartree-Fock procedure, but agreement is improved by comparison with an augmented plane wave energy band calculation carried out by F. J. Arlinghouse (Ph.D. thesis, M.I.T. 1965).

New equipment installed during 1965 included a complete solid state detection unit, comprising a linear amplifier, pulse height analyzer, printing timer and sealer to be used with a scintillation counter. Extensive testing and calibration indicates that long-range stability of better than $1 \%$ is now routinely possible.

The program of surveying compounds for use as standards in terms of absolute intensity measurements was primarily directed at sodium chloride. Techniques of sample preparation, and effects of humidity and of radiation were assessed. No definite conclusions have been made, but it appears that the reproducibility required will be difficult to attain. The change of the integrated intensity with radiation exposure will be further investigated.

The limitations and errors inherent in this technique are now under study. A least-squares fit of the Fourier transform of the scattering factor curve to the radial electron density distribution plus an error curve is being programmed. The effect of termination of series at both low and high $\sin \theta / \lambda$ values is also being considered.

In the parallel program of determining Debye-Waller temperature factors by measuring intensities at a number of different temperatures both copper and sodium chloride were investigated. Experimental values agreed well with the corresponding values from low-temperature specific heat data.

\section{Publications}

G. Burley, Experimental Atomic Scattering Factors for Magnesium Oxide, J. Chem. Phys. Solids, 26, 1605 (1965).

3.8 Deformation and Fracture of Ionic Crystals

S. Wiederhorn

\section{Physical Properties Section}

A new experimental technique has been developed to investigate static fatigue of brittle solids. Using the double-cantilever cleavage arrangement, it was possible to observe crack motion and to 
observe crack motion and to accurately measure crack velocities in glass. Temperature and stress dependence of crack motion in water indicate the observed fracture to be an activated process with an apparent activation energy of $19.5 \mathrm{kcal}$. Crack motion in nitrogen gas is found to be a complicated function of the partial pressure of water vapor in the gas. Three regions of crack motion were delineated. In the first region, crack motion is believed to be due to a chemical reaction between the water vapour and the glass with the interfacial chemical reaction being the rate controlling step. In the second region, crack motion is also due to a chemical reaction between the glass and water vapor, but the rate is controlled by diffusional transport of water vapor to crack tip. A combined rate equation has been developed which satisfactorily explains the experimental data in regions I and II. A satisfactory explanation for crack propagation in region III is not yet available, however, the observed crack motion is independent of moisture content.

The above work will be finished in two months, after which we hope to determine the effect of $\mathrm{pH}$ and impurity ion concentration on crack motion in glass. We also plan to measure the fracture energy of several glasses of different compositions.

\subsection{Crystals of Organic Molecules}

\section{Richard A. Keller and J. John Natterstad}

\section{Physical Chemistry Division}

During the current period the intramolecular energy transfer properties of several molecules containing two different, isolated chromophors were investigated at $77^{\circ} \mathrm{K}$ in rigid glass solutions. A study of the fluorescent and phosphorescent properties of these molecules showed that, in all cases, both singlet and triplet excitation energy is transferred to the chromophor with the lowest singlet or triplet excitation energy. One of the molecules studied had the two chromophors separated 7-12 $\AA$ by a steroid bridge. Several of the molecules had a "spiro" bridge which held the two chromophors perpendicular to each other. Another series of molecules contained two chromophors separated by one, two, and three methylene groups. Work is presently in progress on the study of other chromophors separated by a steroid bridge. 
Papers and Talks

"Formation of Crystallites of Benzophenone in Hydrocarbon Glass", Richard A. Keller and David E. Breen, J. Chem. Phys. 43, 2562 (1965).

"Intramolecular Energy Transfer Between Triplet States of Weakly Interacting Chromophors", David E. Breen and Richard A. Keller, in preparation.

Book review: "Organic Semiconductors" by Y. Okamoto and Walter Brenner, Richard A. Keller, J. Frank. Inst. 279, 391 (1965). 



U.S. DEPARTMENT OF COMMERCE WASHINGTON, D.C. 20230

OFFICIAL BUSINESS
POSTAGE AND FEES PAID

U.S. DEPARTMENT OF COMMERCE 